\title{
Higher Risk of Hypoglycemia with Glimepiride Versus Vildagliptin in Patients with Type 2 Diabetes is not Driven by High Doses of Glimepiride: Divergent Patient Susceptibilities?
}

\author{
Bo Ahrén · James Edward Foley · Sylvie Dejager • Mouna Akacha • \\ Qing Shao • Guenter Heimann • Markus Dworak • Anja Schweizer
}

To view enhanced content go to www.diabetestherapy-open.com

Received: July 28, 2014 / Published online: September 18, 2014

(c) The Author(s) 2014. This article is published with open access at Springerlink.com

\section{ABSTRACT}

Introduction: In a previously published study, vildagliptin showed a reduced risk of hypoglycemia versus glimepiride as add-on therapy to metformin at similar efficacy. Glimepiride was titrated from a starting dose of $2 \mathrm{mg}$ /day to a maximum dose of $6 \mathrm{mg} /$ day. It is usually assumed that the increased hypoglycemia with glimepiride was driven by the $6 \mathrm{mg}$ /day dose; it was therefore of interest to assess whether the risk of hypoglycemia is also

Electronic supplementary material The online version of this article (doi:10.1007/s13300-014-0082-y) contains supplementary material, which is available to authorized users.

B. Ahrén $(\bowtie)$

Lund University, Lund, Sweden

e-mail: bo.ahren@med.lu.se

J. E. Foley · Q. Shao

Novartis Pharmaceuticals Corporation,

East Hanover, NJ, USA

S. Dejager

Novartis Pharma SAS, Rueil Malmaison, France

M. Akacha · G. Heimann · A. Schweizer

Novartis Pharma AG, Basel, Switzerland

M. Dworak

Novartis Pharma GmbH, Nürnberg, Germany different between vildagliptin and a low ( $2 \mathrm{mg}$ / day) dose of glimepiride.

Methods: Data $(n=3,059)$ were from the aforementioned randomized, double-blind study. Comparisons between vildagliptin (50 mg twice daily) and glimepiride (subgroups of patients on $2 \mathrm{mg} /$ day, $6 \mathrm{mg} /$ day, and 'other', and overall glimepiride group) were done by modeling hypoglycemia risk as a function of time and last-measured glycated hemoglobin $\left(\mathrm{HbA}_{1 \mathrm{c}}\right)$ using discrete event time modeling, with treatment, age, gender as additional covariates.

Results: The hypoglycemia risk was significantly lower in patients receiving vildagliptin versus patients remaining on glimepiride $2 \mathrm{mg} /$ day throughout the study, with similar results unadjusted or adjusted for last $\mathrm{HbA}_{1 \mathrm{c}}$ [adjusted hazard ratio $(\mathrm{HR})=0.06$ (95\% CI 0.03, 0.11)]. The risk of hypoglycemia was very low with vildagliptin over the full $\mathrm{HbA}_{1 \mathrm{c}}$ range, while the risk with glimepiride $2 \mathrm{mg} /$ day increased with lower $\mathrm{HbA}_{1 \mathrm{c}}$. The increase for lower levels of $\mathrm{HbA}_{1 \mathrm{c}}$ was more pronounced in the glimepiride $2 \mathrm{mg}$ /day than $6 \mathrm{mg} /$ day subgroup, with the $6 \mathrm{mg} /$ day subgroup showing the lowest hypoglycemia 
risk among the glimepiride groups [adjusted HR vildagliptin vs. $6 \mathrm{mg} /$ day glimepiride $=0.21$ (95\% CI 0.11, 0.40)].

Conclusion: The data show a substantially lower risk of confirmed hypoglycemia with vildagliptin compared to low-dose ( $2 \mathrm{mg} /$ day) glimepiride. The analysis indicates that the previously reported results are not driven by high doses of glimepiride and points to interesting differences among patients regarding the susceptibility to hypoglycemia with sulfonylureas.

Keywords: Dipeptidyl peptidase-4;

Hypoglycemia; Sulfonylurea; Type 2 diabetes; Vildagliptin

\section{INTRODUCTION}

Hypoglycemia is a common problem in patients with type 2 diabetes mellitus (T2DM), occurring most frequently with anti-hyperglycemic treatments increasing insulin levels independently of the blood glucose level, such as oral insulin secretagogues [sulfonylureas [SUs] and glinides] and exogenous insulin. Hypoglycemia is associated with multiple adverse consequences that may, in some cases, counterbalance the benefit of strict glycemic control. Importantly, hypoglycemia is recognized as a major limiting factor for achieving intensive glycemic control in people with T2DM [1, 2] and makes clinicians less likely to implement glycemic targets [3]. Hypoglycemia is also often associated with weight gain due to decreased adherence to diet with "defensive eating" to prevent and/or correct hypoglycemia [4]. Furthermore, severe hypoglycemic events have been associated with an increased risk of cardiovascular complications and death $[5,6]$. Lastly, episodes of hypoglycemia reduce adherence to therapy as well as quality of life [7] and lead to increased medical costs [8].

Unlike indiscriminate insulin secretagogues, such as SUs and glinides, dipeptidyl peptidase-4 (DPP-4) inhibitors regulate glucose homeostasis in a glucose-dependent manner and are, consequently, associated with a low risk of hypoglycemia [9]. In addition to the glucosedependent secretion of insulin and glucagon common to all incretin-based therapies, preservation of glucagon counter-regulation to hypoglycemia has been specifically shown for the DPP-4 inhibitor vildagliptin in several mechanistic studies and is likely a glucosedependent insulinotropic polypeptidemediated effect [9-12].

Clinically, the risk of hypoglycemia was compared between vildagliptin and the SU glimepiride as add-on therapy to metformin in a large, randomized, double-blind study evaluating patients with well-controlled T2DM, but not having reached target, thus being at increased risk for hypoglycemia with additional glucose-lowering therapy $[13,14]$. In this study, patients treated with metformin $(\sim 1,900 \mathrm{mg} /$ day) and a mean baseline glycated hemoglobin $\left(\mathrm{HbA}_{1 \mathrm{c}}\right)$ of $7.3 \%$ were randomized to receive either vildagliptin (50 mg twice daily [bid]) or glimepiride (titrated up to $6 \mathrm{mg} /$ day), with data analyzed after 1 year (interim analysis; $n=2,789)$ [13] and 2 years $(n=3,118)$ [14]. While the efficacy was comparable between the two treatment arms-non-inferiority established at both timepoints-vildagliptin was associated with significant reductions in the frequency and severity of hypoglycemia. Over 1 year, confirmed hypoglycemia was reported in $1.7 \%$ of vildagliptin-treated patients (39 events) compared with $16.2 \%$ of glimepiride-treated patients (554 events, $P<0.01$ ), with 0 vs. 10 severe events $(P<0.01)[13]$. Similar results were also seen after 2 years, with $2.3 \%$ vs. $18.2 \%$ of 
patients, respectively, experiencing hypoglycemia, and a 14 -fold difference in the number of events [14].

Given that glimepiride in the study could be titrated from a starting dose of $2 \mathrm{mg} /$ day to a maximum dose of $6 \mathrm{mg} /$ day, a potential limitation of the study was the perception that the hypoglycemia difference might be driven by high doses of glimepiride, although it is not known whether the risk of hypoglycemia during treatment with glimepiride is dose dependent. The purpose of the present analysis was, therefore, to compare the risk of confirmed hypoglycemia with vildagliptin to the subgroup of glimepiride-treated patients remaining on the dose of $2 \mathrm{mg} /$ day throughout the study. In addition, the study provided the opportunity to assess the hypoglycemia risk of patients tolerating different dose levels of the SU to explore the potential dose dependency of the risk of hypoglycemia for glimepiride. Since differences in $\mathrm{HbA}_{1 \mathrm{c}}$, in particular during the initial 24 weeks of the study where glimepiride was somewhat more efficacious than vildagliptin [13], could have contributed to the difference in hypoglycemia risk between the two treatments, and hypoglycemia is a particular barrier in the lower $\mathrm{HbA}_{1 \mathrm{c}}$ range for achieving glycemic targets, the hypoglycemia potential of the two drugs was assessed in relation to the $\mathrm{HbA}_{1 \mathrm{c}}$ level.

\section{METHODS}

\section{Patients and Study Design}

Data from the aforementioned and previously published, multicenter, randomized, doubleblind study comparing vildagliptin and glimepiride were used for this analysis [13, 14]. In this study, patients with T2DM on stable treatment with metformin and $\mathrm{HbA}_{1 \mathrm{c}}$ of $6.5-8.5 \%$ were randomized $1: 1$ to receive vildagliptin $50 \mathrm{mg}$ bid or glimepiride for 104 weeks. Glimepiride was started at a dose of $2 \mathrm{mg} /$ day and could be up-titrated to a maximum of $6 \mathrm{mg} / \mathrm{day}$.

\section{Assessments}

Hypoglycemia was defined as symptoms suggestive of low blood glucose confirmed by self-monitored blood glucose (SMBG) measurement $<3.1 \mathrm{mmol} / \mathrm{L}$ plasma glucose equivalent. $\mathrm{HbA}_{1 \mathrm{c}}$ was measured regularly in the study and analyzed by a central laboratory (Covance Central Laboratory Services).

\section{Data Analysis}

The total number of patients and demography/ baseline characteristics are presented for the vildagliptin group, the glimepiride $2 \mathrm{mg} /$ day, $6 \mathrm{mg} /$ day and 'other' subgroups, and the overall glimepiride group for the intent-to-treat (ITT) population.

The glimepiride subgroups were defined as follows: the $2 \mathrm{mg} /$ day subgroup included all patients who remained on glimepiride $2 \mathrm{mg} /$ day throughout their entire study duration; the $6 \mathrm{mg} /$ day subgroup included all patients who were either up-titrated to $6 \mathrm{mg} /$ day by week 16 latest and subsequently stayed on this dose level throughout the remainder of their study duration or discontinued up to week 16 with $6 \mathrm{mg} /$ day as their last dose; and the 'other' subgroup consisted of all remaining glimepiride-treated patients.

The reported post hoc analysis was done in the ITT population using discrete event-time modeling [15], following the approach in a recently published paper [16]. Hypoglycemic risk was modeled as a function of time and last- 
measured $\mathrm{HbA}_{1 \mathrm{c}}$, with treatment (or subgroup) and gender included as additional covariates. All hazard ratios (HRs) were estimated from this model, with the unadjusted hazard rates ignoring last-measured $\mathrm{HbA}_{1 \mathrm{c}}$ as a covariate. Further details are presented in ESM Appendix 1.

While all data over the entire study duration were used in the modeling, it was chosen to predict the hypoglycemia risk for week 24 as the minimum duration of most standard clinical trials is 24 weeks and it falls into the main period where the SU was somewhat more efficacious than vildagliptin [13]. In addition, this time point ensured a more robust assessment compared with the later stages of the study when an increasing number of discontinuations occurred.

Mean changes from baseline in $\mathrm{HbA}_{1 \mathrm{c}}$ at week 24 in the vildagliptin group, the different glimepiride subgroups and the overall glimepiride group were analyzed using last observation carried forward in the ITT population. Within-group comparisons (endpoint vs. baseline) were made using one sample $t$ test at a significance level of 0.05 .

\section{Ethics and Good Clinical Practice}

All study participants provided written informed consent. The protocol was approved by the independent ethics committee/institutional review board at each study site or country. The study was conducted using good clinical practice and in accordance with the Declaration of Helsinki.

\section{RESULTS}

\section{Demography}

Table 1 summarizes the demographic and baseline characteristics of patients in the vildagliptin $50 \mathrm{mg}$ bid $(n=1,539)$, glimepiride
$2 \mathrm{mg} /$ day $\quad(n=417), \quad$ glimepiride $6 \mathrm{mg} /$ day $(n=589)$, glimepiride 'other' $(n=514)$ and overall glimepiride $(n=1,520)$ groups. The demographic and baseline characteristics were overall comparable across the vildagliptin and glimepiride groups (Table 1). The patients studied in the different groups had a mean age of $56-59$ years, $53-54 \%$ were men and the vast majority (82-91\%) were Caucasian. Mean $\mathrm{HbA}_{1 \mathrm{c}}$ was $7.0-7.5 \%$, mean body mass index was $31-32 \mathrm{~kg} / \mathrm{m}^{2}$ and mean duration of diagnosed T2DM was 5-6 years, with a mean duration of metformin use of 2.8-3.1 years (mean dose 1,853-1,902 mg/day). More than two-thirds of patients (64-73\%) had normal renal function and renal impairment was predominantly mild in the remaining patients.

\section{Risk of Confirmed Hypoglycemia}

The analysis showed that the risk of confirmed hypoglycemia was significantly lower in patients treated with vildagliptin $50 \mathrm{mg}$ bid compared with patients who remained on glimepiride $2 \mathrm{mg}$ /day for their entire study duration ( $2 \mathrm{mg}$ /day subgroup), with similar results unadjusted $[\mathrm{HR}=0.04 \quad(95 \%$ CI 0.02 , 0.08); $P<0.0001]$ or adjusted for last-measured $\mathrm{HbA}_{1 \mathrm{c}} \quad[\mathrm{HR}=0.06 \quad(95 \% \quad \mathrm{CI} \quad 0.03, \quad 0.11)$; $P<0.0001]$. As shown in Fig. 1 , the risk of hypoglycemia was very low with vildagliptin over the full $\mathrm{HbA}_{1 \mathrm{c}}$ range while the risk with glimepiride $2 \mathrm{mg} /$ day increased with lower $\mathrm{HbA}_{1 \mathrm{c}}$. The increase for lower levels of $\mathrm{HbA}_{1 \mathrm{c}}$ was more pronounced in the glimepiride $2 \mathrm{mg}$ / day subgroup than in the full set of patients treated with glimepiride (Fig. 1). The HR of vildagliptin versus the overall glimepiride

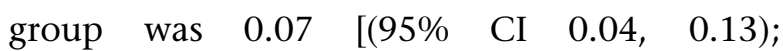
$P<0.0001]$ unadjusted and $0.08 \quad[(95 \% \mathrm{CI}$ $0.05,0.15) ; \quad P<0.0001]$ adjusted for lastmeasured $\mathrm{HbA}_{1 \mathrm{c}}$. 


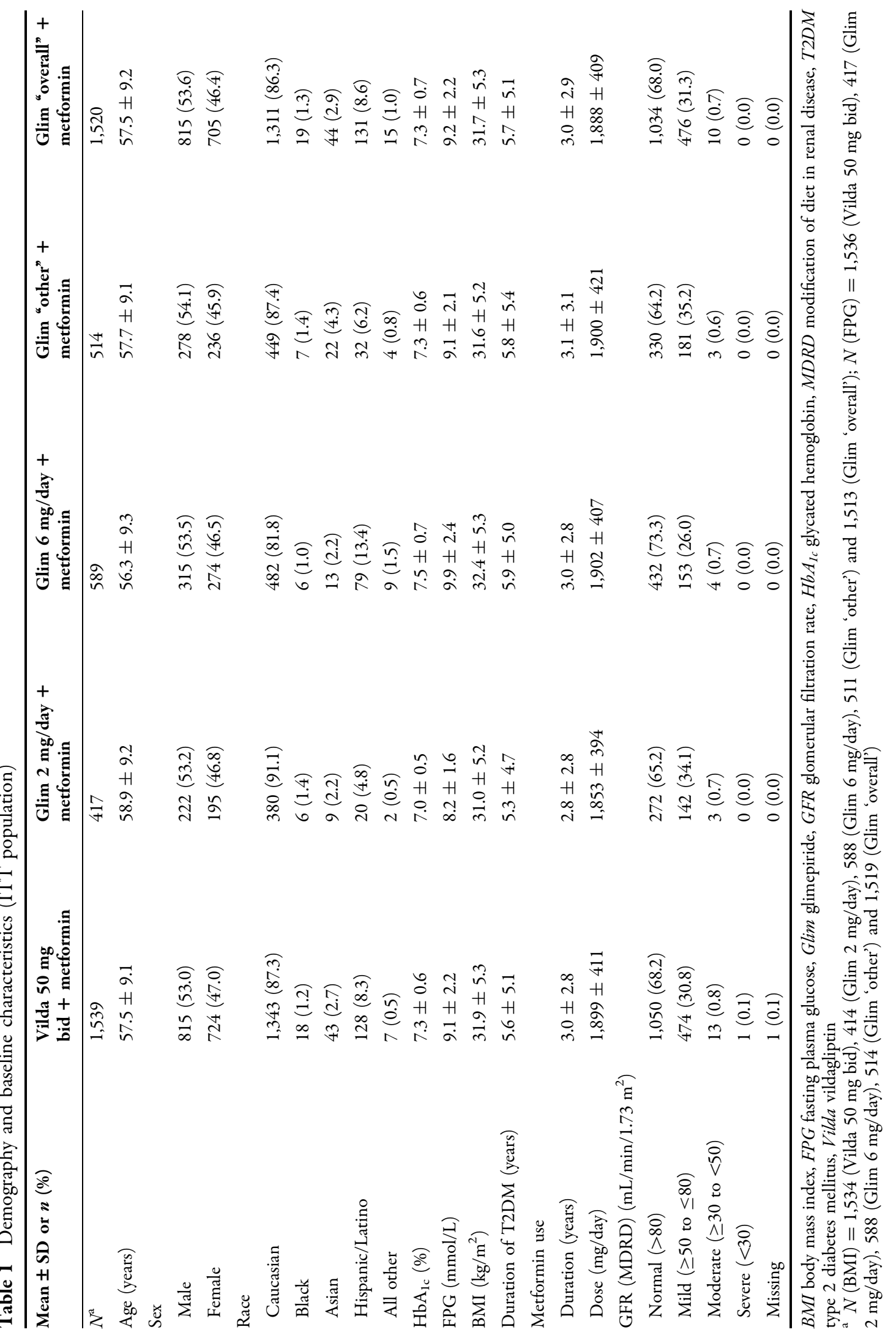




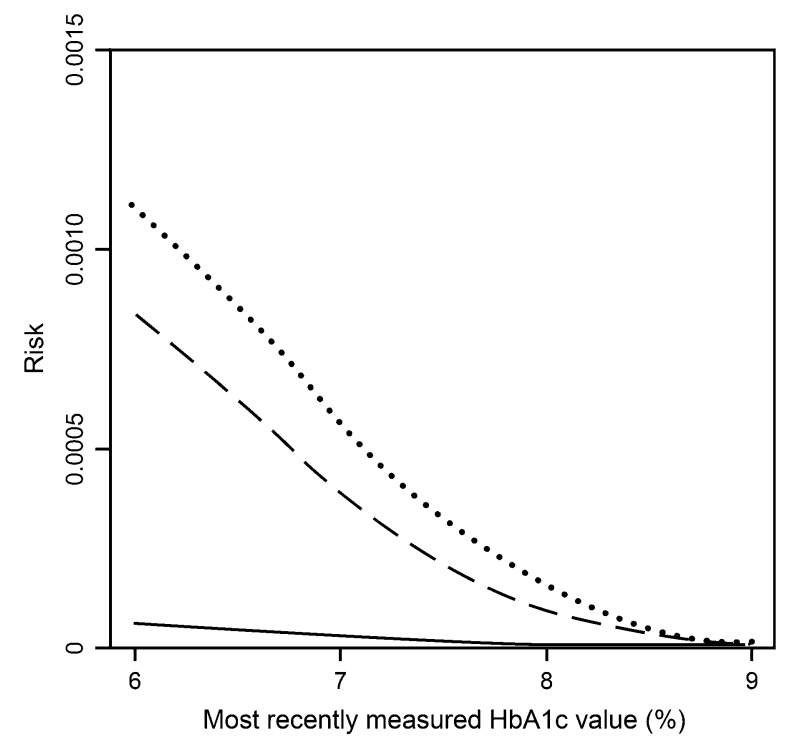

Fig. 1 Risk of confirmed hypoglycemia as a function of the most recently measured glycated hemoglobin $\left(\mathrm{HbA}_{1 \mathrm{c}}\right)$ in patients with type 2 diabetes mellitus after treatment with vildagliptin $50 \mathrm{mg}$ bid + metformin (solid line; $n=1,539$ ), glimepiride 'overall' + metformin (dashed line; $n=1,520$ ) or glimepiride $2 \mathrm{mg} /$ day + metformin (dotted line; $n=417$ ). Risks are shown for week 24 [intent-to-treat (ITT) population]

To further assess the hypoglycemia risk of patients on different dose levels of glimepiride, in addition to the low-dose ( $2 \mathrm{mg}$ /day) subgroup, analyses were also performed for the high-dose (6 mg/day) subgroup and the 'other' subgroup (comprising all remaining glimepiride-treated patients). As shown in Fig. 2, among the glimepiride groups, the $2 \mathrm{mg}$ /day subgroup had the highest increase in hypoglycemia risk for lower levels of $\mathrm{HbA}_{1 \mathrm{c}}$, while this increase in hypoglycemia risk was least pronounced in the $6 \mathrm{mg} /$ day subgroup. The 'other' subgroup had an intermediate risk, although the difference between the $2 \mathrm{mg}$ /day subgroup and the 'other' subgroup was small. The HR of vildagliptin versus $6 \mathrm{mg} /$ day glimepiride was 0.22 [( $95 \%$ CI $0.12,0.43)$; $P<0.0001]$ unadjusted and $0.21 \quad[(95 \% \mathrm{CI}$ $0.11,0.40) ; \quad P<0.0001]$ adjusted for lastmeasured $\mathrm{HbA}_{1 \mathrm{c}}$, and this was 0.06 [(95\% CI

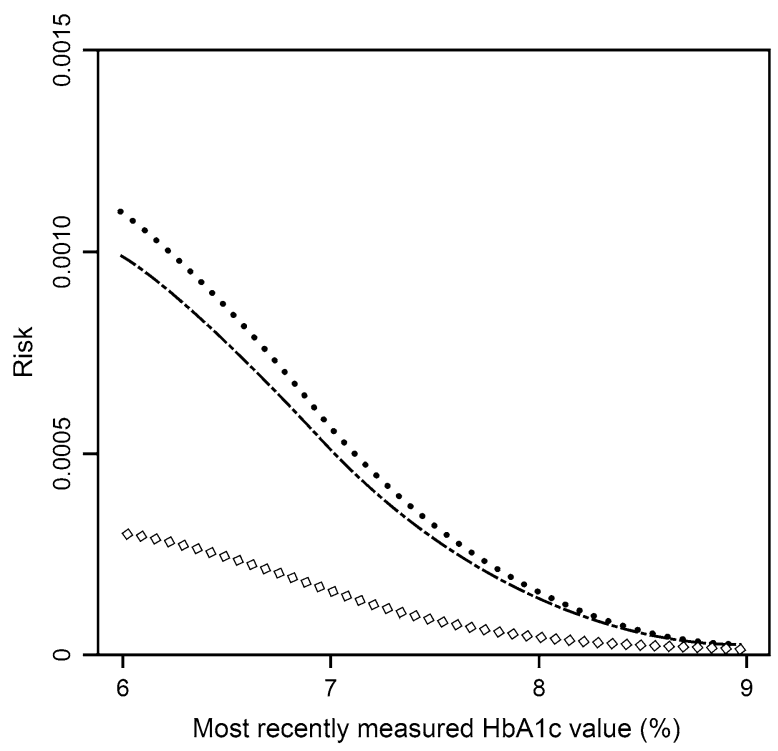

Fig. 2 Risk of confirmed hypoglycemia as a function of the most recently measured glycated hemoglobin $\left(\mathrm{HbA}_{1 \mathrm{c}}\right)$ in patients with type 2 diabetes mellitus after treatment with glimepiride $6 \mathrm{mg} /$ day + metformin (open diamond; $n=589$ ), glimepiride "other" + metformin (dash dotted line; $n=514$ ) or glimepiride $2 \mathrm{mg} /$ day + metformin (dotted line; $n=417$ ). Risks are shown for week 24 [intent-to-treat (ITT) population]

$0.03,0.10) ; P<0.0001]$ and 0.07 [(95\% CI 0.04, 0.12); $\quad P<0.0001]$, respectively, for the glimepiride 'other' subgroup.

\section{Changes in $\mathrm{HbA}_{1 \mathrm{c}}$}

While the hypoglycemia analyses were adjusted for last-measured $\mathrm{HbA}_{1 \mathrm{c}}$, for completeness, changes in $\mathrm{HbA}_{1 \mathrm{c}}$ were also evaluated. Figures 1 and 2 show the hypoglycemia risk as predicted for week 24 (see "Methods" for details); for comparison, changes in $\mathrm{HbA}_{1 \mathrm{c}}$ were assessed at week 24. In each group, a highly significant mean change in $\mathrm{HbA}_{1 \mathrm{c}}$ from baseline to week 24 was observed. The decreases in $\mathrm{HbA}_{1 \mathrm{c}}$ were $-0.5 \pm 0.02 \%$ (baseline $7.3 \%$ ) in the vildagliptin $50 \mathrm{mg}$ bid group, $-0.6 \pm 0.03 \%$ (baseline $7.0 \%$ ) in the glimepiride $2 \mathrm{mg}$ /day subgroup, $-0.7 \pm 0.03 \%$ (baseline $7.5 \%$ ) in the glimepiride $6 \mathrm{mg}$ /day subgroup, $-0.7 \pm 0.03 \%$ 
(baseline 7.3\%) in the glimepiride 'other' subgroup and $-0.7 \pm 0.02 \%$ (baseline $7.3 \%$ ) in the overall glimepiride group $(P<0.0001$ vs. baseline in all groups). Thus, the week 24 endpoint mean $\mathrm{HbA}_{1 \mathrm{c}}$ was $<7 \%(6.4-6.8 \%)$ in all groups.

\section{DISCUSSION}

In a previously published study (mean $\mathrm{HbA}_{1 \mathrm{c}}$ $7.3 \%$ ), vildagliptin (50 mg bid) showed a markedly reduced risk of hypoglycemia compared with glimepiride as add-on therapy to metformin at similar efficacy $[13,14]$. However, since glimepiride was titrated from a starting dose of $2 \mathrm{mg} /$ day to a maximum dose of $6 \mathrm{mg} /$ day, one limitation of the trial was the perception that the SU dose was titrated to too high doses and the hypoglycemia difference was driven by the highest glimepiride dose of $6 \mathrm{mg} /$ day. The present analysis, however, clearly showed a substantially lower risk of confirmed hypoglycemia with vildagliptin when compared with low-dose ( $2 \mathrm{mg} /$ day) glimepiride. In addition, while all glimepiride subgroups showed a higher risk than the vildagliptin group, among the glimepiride groups the hypoglycemia risk was, against common perception, more pronounced in the glimepiride $2 \mathrm{mg}$ /day subgroup than in the glimepiride $6 \mathrm{mg} /$ day subgroup. Thus, the previously reported hypoglycemia results were not driven by high doses of glimepiride and an inverse relationship between the glimepiride dose and hypoglycemia risk was observed.

An additional limitation of the original study concerned the possibility that differences in $\mathrm{HbA}_{1 \mathrm{c}}$ reductions/levels of $\mathrm{HbA}_{1 \mathrm{c}}$ in particular during the initial 24 weeks of the study, where glimepiride was somewhat more efficacious than vildagliptin [13], could have contributed to the difference in hypoglycemia risk between vildagliptin and glimepiride. In the present analysis, the hypoglycemia risk was, therefore, assessed in relation to the last-measured $\mathrm{HbA}_{1 \mathrm{c}}$ level using discrete event-time modeling. The reduced risk of hypoglycemia with vildagliptin versus glimepiride remained essentially unchanged when adjusted for the most recently measured $\mathrm{HbA}_{1 \mathrm{c}}$ level, as seen from the very similar HRs unadjusted and adjusted for all groups of glimepiride. Hence, it is unlikely that differences in hypoglycemic risk between the two groups can be attributed to differences in $\mathrm{HbA}_{1 \mathrm{c}}$ reductions. The analysis further showed that, as expected, the difference between the two treatments increased with increasingly lower $\mathrm{HbA}_{1 \mathrm{c}}$ levels. A limitation remains that the most recently measured $\mathrm{HbA}_{1 \mathrm{c}}$ value associated with the hypoglycemic event was used in the analysis, while the $\mathrm{HbA}_{1 \mathrm{c}}$ at the time of the hypoglycemia event was usually not available. The adjustment for last-measured $\mathrm{HbA}_{1 \mathrm{c}}$ was also relevant when comparing the hypoglycemia risk between the glimepiride groups as it needs to be acknowledged that the baseline $\mathrm{HbA}_{1 \mathrm{c}}$ level was somewhat lower in the glimepiride $2 \mathrm{mg} /$ day subgroup than the glimepiride $6 \mathrm{mg} /$ day subgroup; on the other hand, the glycemic levels were very low in all subgroups, so that the small differences could not have been expected to drive a major difference in hypoglycemia risk.

While the difference in hypoglycemia risk between vildagliptin and glimepiride manifests independent of the dose level, the at-firstglance unexpected finding of an inverse relationship between the glimepiride dose and hypoglycemia risk seen in the present assessment merits further comment. A potential explanation could be linked to the known attenuation of glucagon counterregulation seen in T2DM [17]; it seems 
reasonable to assume that this impairment in glucagon counter-regulation varies among patients secondary to a progressive reduction in the sensitivity of the $\alpha$-cell to glucose. In addition, there is a variable amount of residual glucose-sensitive insulin secretion among different patients. The progression of T2DM is associated with a progressive decline in $\beta$-cell function/sensitivity [18], the degree of this loss varies between different patients and some individuals have very little remaining $\beta$-cell glucose sensitivity [19]. In patients with more residual $\beta$-cell sensitivity to glucose on top of the SU-induced glucose-independent insulin secretion, there is a faster postprandial $\beta$-cell response to increase insulin secretion, followed by a faster $\beta$-cell response to reduce insulin secretion when glucose levels fall [20, 21]. Thus, patients, who have lost much of their ability to secrete both insulin and glucagon in a glucosesensitive manner, can be expected to be more susceptible to hypoglycemia induced by medications that stimulate insulin secretion in a glucose-independent manner. Consequently, such patients would have been more likely to have their glimepiride dose restricted to the lowest dose level of $2 \mathrm{mg} /$ day in the study underlying the present analysis and even at this dose they would still have a higher risk of hypoglycemia compared with other patients with more residual glucose sensitivity. The latter patients would consequently also be more likely to tolerate high doses of SUs, which could provide an explanation for the lower hypoglycemia risk observed in the $6 \mathrm{mg}$ / day subgroup compared with the $2 \mathrm{mg}$ /day subgroup in the present analysis. Interestingly, a similar observation was previously made in a double-blind study comparing gliclazide modified release (MR; titrated from $30 \mathrm{mg}$ /day to a maximum of $120 \mathrm{mg} /$ day) and glimepiride (titrated from $1 \mathrm{mg} /$ day to a maximum of $6 \mathrm{mg} /$ day) [22], suggesting that this could be a general finding with SUs. In both treatment groups, most hypoglycemic events occurred at the two lowest treatment doses (representing $\sim 51 \%$ of the study population); of 22 events with gliclazide MR, there were 13 and 2 events with the $30 \mathrm{mg}$ and $60 \mathrm{mg}$ dose, respectively, and of 56 events with glimepiride, there were 21 and 27 events with the $1 \mathrm{mg}$ and $2 \mathrm{mg}$ doses, respectively [22]. While patients who are less susceptible to hypoglycemia under SU treatment obviously exist, a clear limitation in clinical practice is that it is not possible to predict which patients are more or less sensitive, unless they are actually exposed to SU treatment and potential hypoglycemia to determine their hypoglycemia risk. In addition, while some patients may start with a lower risk of hypoglycemia with SUs, it is not clear what will happen over time as T2DM progresses and islet cell function further deteriorates.

In contrast to the SUs that stimulate insulin secretion in a glucose-independent manner, increase insulin capacity even at low glucose concentrations [23, 24] and can significantly impair glucagon counter-regulation (as shown for both tolbutamide and glibenclamide) [25, 26], DPP-4 inhibitors, such as vildagliptin, have been shown to stimulate insulin secretion and inhibit glucagon secretion in a glucosedependent manner [9]. In addition, at hypoglycemic levels, preserved glucagon counter-regulation has been explicitly demonstrated for vildagliptin in several studies and patient groups $[10,11,27]$. These effects underlie the low propensity of vildagliptin to cause hypoglycemia, even at low levels of glycemia and across different patient groups and disease states $[9,28,29]$. 


\section{CONCLUSION}

Taken together, the data show a substantially lower risk of confirmed hypoglycemia with vildagliptin compared with low-dose $(2 \mathrm{mg} /$ day) glimepiride and also reveal an inverse relationship between glimepiride dose and hypoglycemia risk. Thus, the additional analyses presented here further extend the knowledge/understanding on the differences between vildagliptin and the SU glimepiride with respect to the risk of hypoglycemia and point to interesting differences among patients with T2DM regarding the susceptibility to hypoglycemia with SUs.

\section{ACKNOWLEDGMENTS}

This study was funded by Novartis Pharma AG. The authors gratefully acknowledge all the investigators, staff and patients at the participating sites, and Anil Dandu (Novartis Healthcare Pvt. Ltd.) for technical help. All named authors meet the ICMJE criteria for authorship for this manuscript, take responsibility for the integrity of the work as a whole, and have given final approval for the version to be published.

Conflict of interest. B. Ahrén has consulted for Novartis, GlaxoSmithKline, Merck, Sanofi, Novo Nordisk, Boehringer Ingelheim and Takeda, and has received lecture fees from Novartis, Merck, Novo Nordisk, Sanofi, Bristol Myers Squibb, AstraZeneca and GlaxoSmithKline. A. Schweizer is employed by Novartis and own shares. S. Dejager is employed by Novartis. M. Dworak is employed by Novartis and own shares. G. Heimann is employed by Novartis and own shares. M. Akacha is employed by Novartis and own shares.
Q. Shao is employed by Novartis and own shares. J. E. Foley is employed by Novartis and own shares.

Compliance with ethics guidelines. The study protocol was reviewed and approved by the Independent Ethics Committee/ Institutional Review Board at each center. All procedures followed were in accordance with the ethical standards of the responsible committee on human experimentation (institutional and national), the Helsinki Declaration of 1975, as revised in 2000 and 2008, and Good Clinical Practice guidelines. Informed consent was obtained from all patients for being included in the study.

Open Access. This article is distributed under the terms of the Creative Commons Attribution Noncommercial License which permits any noncommercial use, distribution, and reproduction in any medium, provided the original author(s) and the source are credited.

\section{REFERENCES}

1. Briscoe VJ, Davis SN. Hypoglycemia in type 1 and type 2 diabetes: physiology, pathophysiology, and management. Clin Diabetes. 2006;24:115-21.

2. Cryer PE. Glycemic goals in diabetes: trade-off between glycemic control and iatrogenic hypoglycemia. Diabetes. 2014;63:2188-95.

3. Cryer PE. Hypoglycemia: the limiting factor in the glycemic management of type I and type II diabetes. Diabetologia. 2002;45:937-48.

4. Foley JE, Jordan J. Weight neutrality with the DPP-4 inhibitor, vildagliptin: mechanistic basis and clinical experience. Vasc Health Risk Manag. 2010;6:541-8.

5. Barnett AH. Avoiding hypoglycaemia while achieving good glycaemic control in type 2 diabetes through optimal use of oral agent therapy. Curr Med Res Opin. 2010;26:1333-42. 
6. Bonds DE, Miller ME, Bergenstal RM, Buse JB, Byington RP, Cutler JA, et al. The association between symptomatic, severe hypoglycaemia and mortality in type 2 diabetes: retrospective epidemiological analysis of the ACCORD study. BMJ. 2010;340:b4909.

7. McEwan $\mathrm{P}$, Evans $\mathrm{M}$, Kan $\mathrm{H}$, Bergenheim $\mathrm{K}$. Understanding the inter-relationship between improved glycaemic control, hypoglycaemia and weight change within a long-term economic model. Diabetes Obes Metab. 2010;12:431-6.

8. Jönsson L, Bolinder B, Lundkvist J. Cost of hypoglycemia in patients with type 2 diabetes in Sweden. Value Health. 2006;9:193-8.

9. Ahrén B, Schweizer A, Dejager S, Villhauer EB, Dunning BE, Foley JE. Mechanisms of action of the dipeptidyl peptidase-4 inhibitor vildagliptin in humans. Diabetes Obes Metab. 2011;13:775-83.

10. Ahrén B, Schweizer A, Dejager S, Dunning BE, Nilsson PM, Persson M, et al. Vildagliptin enhances islet responsiveness to both hyper- and hypoglycemia in patients with type 2 diabetes. J Clin Endocrinol Metab. 2009;94:1236-43.

11. Farngren J, Persson M, Schweizer A, Foley JE, Ahrén B. Glucagon dynamics during hypoglycaemia and food-re-challenge following treatment with vildagliptin in insulin-treated patients with type 2 diabetes. Diabetes Obes Metab. 2014;16:812-8.

12. Christensen M, Vedtofte L, Holst JJ, Vilsbøll T, Knop FK. Glucose-dependent insulinotropic polypeptide: a bifunctional glucose-dependent regulator of glucagon and insulin secretion in humans. Diabetes. 2011;60:3103-9.

13. Ferrannini E, Fonseca V, Zinman B, Matthews D, Ahrén B, Byiers S, et al. Fifty-two-week efficacy and safety of vildagliptin vs. glimepiride in patients with type 2 diabetes mellitus inadequately controlled on metformin monotherapy. Diabetes Obes Metab. 2009;11:157-66.

14. Matthews DR, Dejager S, Ahrén B, Fonseca V, Ferrannini E, Couturier A, et al. Vildagliptin addon to metformin produces similar efficacy and reduced hypoglycaemic risk compared with glimepiride, with no weight gain: results from a 2-year study. Diabetes Obes Metab. 2010;12:780-9.

15. Willet JB, Singer JD. It's Déjà Vu all over again: using multiple-spell discrete time survival analysis. J Educ Behav Stat. 1995;20:41-67.

16. Krobot KJ, Ferrante SA, Davies MJ, Seck T, Meininger GE, Williams-Herman D, et al. Lower risk of hypoglycemia with sitagliptin compared to glipizide when either is added to metformin therapy: a pre-specified analysis adjusting for the most recently measured HbA1c value. Curr Med Res Opin. 2012;28:1281-7.

17. Bolli GB, Tsalikian E, Haymond MW, Cryer PE, Gerich JE. Defective glucose counterregulation after subcutaneous insulin in noninsulin-dependent diabetes mellitus. Paradoxical suppression of glucose utilization and lack of compensatory increase in glucose production, roles of insulin resistance, abnormal neuroendocrine responses, and islet paracrine interactions. J Clin Invest. 1984;73:1532-41.

18. Kahn SE. Clinical review 135: the importance of beta-cell failure in the development and progression of type 2 diabetes. J Clin Endocrinol Metab. 2001;86:4047-58.

19. Michaliszyn SF, Mari A, Lee S, Bacha F, Tfayli $H$, Farchoukh L, et al. $\beta$-Cell function, incretin effect, and incretin hormones in obese youth along the span of glucose tolerance from normal to prediabetes to type 2 diabetes. Diabetes 2014 [Epub ahead of print].

20. Kahn SE, Montgomery B, Howell W, LiguerosSaylan M, Hsu CH, Devineni D, et al. Importance of early phase insulin secretion to intravenous glucose tolerance in subjects with type 2 diabetes mellitus. J Clin Endocrinol Metab. 2001;86:5824-9.

21. Mari A, Gastaldelli A, Foley JE, Pratley RE, Ferrannini E. Beta-cell function in mild type 2 diabetic patients: effects of 6-month glucose lowering with nateglinide. Diabetes Care. 2005;28:1132-8.

22. Schernthaner G, Grimaldi A, Di Mario U, Drzewoski J, Kempler P, Kvapil M, et al. GUIDE study: doubleblind comparison of once-daily gliclazide MR and glimepiride in type 2 diabetic patients. Eur J Clin Invest. 2004;34:535-42.

23. Davidson MB. Pathogenesis of impaired glucose tolerance and type II diabetes mellitus-current status. West J Med. 1985;142:219-29.

24. Krentz AJ, Bailey CJ. Oral antidiabetic agents: current role in type 2 diabetes mellitus. Drugs. 2005;65:385-411.

25. Landstedt-Hallin L, Adamson U, Lins PE. Oral glibenclamide suppresses glucagon secretion during insulin-induced hypoglycemia in patients with type 2 diabetes. J Clin Endocrinol Metab. 1999;84:3140-5.

26. Peacey SR, Rostami-Hodjegan A, George E, Tucker GT, Heller SR. The use of tolbutamide-induced hypoglycemia to examine the intraislet role of insulin in mediating glucagon release in normal 
humans. J Clin Endocrinol Metab. 1997;82:1458-61.

27. Farngren J, Persson M, Schweizer A, Foley JE, Ahrén B. Vildagliptin reduces glucagon during hyperglycemia and sustains glucagon counterregulation during hypoglycemia in type 1 diabetes. J Clin Endocrinol Metab. 2012;97:3799-806.
28. Schweizer A, Foley JE, Kothny W, Ahrén B. Clinical evidence and mechanistic basis for vildagliptin's effect in combination with insulin. Vasc Health Risk Manag. 2013;9:57-64.

29. Dejager S, Schweizer A, Foley JE. Evidence to support the use of vildagliptin monotherapy in the treatment of type 2 diabetes mellitus. Vasc Health Risk Manag. 2012;8:339-48. 